RGSA - Revista de Gestão Social e Ambiental

ISSN: $1981-982 X$

Data de submissão: $28 / 12 / 2021$

Data de aceite: 05/12/2021

REVISTA DE GESTÃO SOCIAL E AMBIENTAL

DOI: https://doi.org/10.24857/rgsa.v15.2812

Organização: Comitê Científico Interinstitucional

Editora Chefe: Eliana Andréa Severo

Avaliação: Double Blind Review pelo SEER/OJS

\title{
GERENCIAMENTO DE RESÍDUOS DO ÓLEO LUBRIFICANTE: UMA REVISÃO SISTEMÁTICA DA LITERATURA
}

\section{RESUMO}

Neide da Cruz Gonzaga ${ }^{1}$

Romário Nunes da Silva ${ }^{2}$

Luciano Pires de Andrade ${ }^{3}$

Objetivo: analisar a importância econômica e ambiental do processo de rerrefino do óleo lubrificante usado ou contaminado, bem como, debater o seu atualcenário.

Referencial teórico: A Associação Brasileira de Normas Técnicas NBR 10004 (ABNT), classifica o Óleo Lubrificante Usado ou Contaminado (OLUC) como resíduo perigoso. O gerenciamento correto do OLUC torna-se um desafio da sociedade atual, sendo imprescindível que se realize a sua reciclagem por meio do processo de rerrefino, a fim de evitar a conta minação da água, do solo e do ar.

Método: foi realizada uma revisão sistemática da literatura a partir do resgate de artigos científicos indexados nas bases de dados da Scielo, Scopus e Google Scholar. Após uma breve triagem, foram selecionadas 16 experiências.

Resultados e conclusão: o gerenciamento adequado dos óleos lubrificantes usados se alinha com ideias discutidas mundialmente, em termos de desenvolvimento sustentável, trazendo benefícios significativos na esfera social, econômica e ambiental. No entanto, faz-se necessário reestruturar práticas de gerenciamento do resíduo e ações para aumentaro desempenho da logística reversa.

Implicações da pesquisa: estímulo a o debate em torno da problemática do descarte do óleo contaminado ou u sa do no meio a mbiente, como ta mbém, repensar maneiras de reuso de produtos perigosos.

Originalidade/valor: identificou os impactos que o gerenciamento incorreto do óleo lubrificante usado ou contaminado pode causare pontuou os benefícios para a conservação a mbiental, justiça social e o crescimento econômico.

Palavras-chave: Logística Reversa. Meio Ambiente. Rerrefino. Sustentabilidade.

RGSA adota a Licença de Atribuição CC BY do Creative Commons (https://creativecommons.org/licenses/by/4.0/).

\footnotetext{
${ }^{1}$ Mestranda em Ciências Ambientais pela Universidade Federal do Agreste de Pernambuco - UFAPE, Pernambuco (Brasil). Email: gonzaganeide361@gmail.com Orcid: https://orcid.org/0000-0002-2977-0020

2 Mestrando em Ciências Ambientais, Universidade Federal do Agreste de Pernambuco - UFAPE/Garanhuns, Pernambuco (Brasil). Email: romario.nuness@ gmail.com Orcid: https://orcid.org/0000-0002-0401-8000

${ }^{3}$ Doutor em Etnobiologia e Conservação da Natureza e professor na Universidade Federal do Agreste de Pernambuco UFAPE, Garanhuns, Pernambuco (Brasil). Email: lucianopandrade@gmail.com Orcid: https://orcid.org/0000-0001$\underline{5818-711 X}$
}

\begin{tabular}{|l|l|l|l|l|l|}
\hline Rev. Gest. Soc. Ambient. & São Paulo (SP) & v.15 & p.01-16 & e02812 & 2021. \\
\hline
\end{tabular}




\title{
LUBRICANT OIL WASTE MANAGEMENT: A SYSTEMATIC LITERATURE REVIEW
}

\begin{abstract}
Purpose: to analyze the economic and environmental importance of the re-refining process of used or contaminated lubricating oil, as well as to debate its current scenario.

Theoretical framework: The Brazilian Association of Technical Standards NBR 10004 (ABNT), classifies Used or Contaminated Lubricant Oil (OLUC) as hazardous waste. The correct management of OLUC becomes a challenge for today's society, and it is essential to carry out its recycling through the re-refining process, in order to avoid contamination of water, soil and air.
\end{abstract}

Method/design/approach: a systematic literature review was carried out based on the retrieval of scientific articles indexed in Scielo, Scopus and Google Scholar databases. After a brief screening, 16 experiments were selected.

Results and conclusion: the proper management of used lubricating oils is in line with ideas discussed worldwide, in terms of sustainable development, bringing significant benefits in the social, economic and environmental sphere. However, it is necessary to restructure waste management practices and actions to increase the performance of reverse logistics.

Research implications: stimulating debate around the issue of disposing of contaminated or used oil in the environment, as well as rethinking ways of reusing hazardous products.

Originality/value: identified the impacts that the incorrect management of used or contaminated lubricating oil can cause and scored the benefits for environmentalconservation, socialjustice and economic growth.

Keywords: Reverse logistic. Environment. Re-refining. Sustainability.

\section{INTRODUÇÃO}

Após a Revolução Industrial, a humanidade tem observado, por meio das mudanças climáticas e da escassez de recursos não renováveis, os efeitos causados pelo desenvolvimento gerado de forma desequilibrada. O crescimento econômico tem repousado no uso insustentável de recursos naturais e na degradação do meio ambiente (Martine \& Alves, 2018).

A questão ambiental é um dos mais importantes desafios da sociedade. Nas últimas décadas, documentos importantes com diretrizes pautadas na sustentabilidade foram formalizados. A Agenda 21, publicada em 1995, foi elaborada pelos participantes da Conferência Rio/92, a Cúpula da Terra, e estimulou um consenso mundial e um compromisso político, pautado na elaboração de planos de ação que vão ao encontro da sustentabilidade no âmbito mundial. Em 2015, foi aprovada a Agenda 2030, na Cúpula de Desenvolvimento Sustentável, compreendendo 169 metas e 231 indicadores globais, direcionados à erradicação da pobreza, à redução das desigualdades, ao enfrentamento das mudanças climáticas e à promoção do crescimento econômico, tudo em harmonia com as dimensões do desenvolvimento sustentável, quais sejam: econômica, social e ambiental (ONU, 2015).

O sexto Relatório IPCC - Painel Intergovernamental sobre Mudanças Climáticas alertou que o aumento de dióxido de carbono na atmosfera está associado diretamente à atividade humana, em sua maioria, em razão da exploração do petróleo, queima de carvão e de outros combustíveis fósseis (IPCC, 2021). Ademais, recentemente, na COP26, Conferência realizada na Escócia, 196 
nações signatárias do Acordo de Paris se reuniram para discutir desenvolvimento, preservação do meio ambiente e ações que possam conter o aquecimento global (Brasil, 2021).

Nos dias atuais, a consciência ambiental no meio empresarial é de extrema relevância e a logística reversa, se destaca como um instrumento que proporciona a economia de energia, a redução de resíduos, o uso de recursos naturais pelo maior tempo possível, a redução da importação de petróleo e a estabilização do consumo de um recurso caro e finito, podendo contribuir efetivamente para reduzir a emissão de GEE lançados no meio ambiente (Rac \& Vencl, 2012; Capello et al., 2015; Stocker et al., 2020; Izza et al., 2018).

A procura por soluções para os resíduos sólidos sob a premissa do desenvolvimento sustentável deve abarcar um conjunto de ações, devendo ser compartilhada pelos responsáveis públicos ou privados, com qualidade essencial para alcançar o princípio da ecoeficiência. A qualidade se torna um elemento crucial para obter sucesso em atender as necessidades pertinentes, o que inclui a qualidade consistente na gestão da logística reversa (Nikolaidis, 2013).

Nesse sentido, as questões relacionadas à sustentabilidade têm chamado a atenção do poder público e constituem uma referência para assegurar o desenvolvimento econômico, com práticas que possam inibir danos à saúde pública e ao meio ambiente. O manejo e descarte correto do óleo lubrificante pelas empresas é extremamente relevante, vez que é uma temática que transcende as vantagens econômicas envolvidas (Amarante, 2019).

O consumismo desenfreado aliado à falta de padrões sustentáveis acarreta no aumento da geração de resíduos sólidos, que necessitam de cuidados específicos em sua destinação final, dentre eles, o Óleo Lubrificante Usado ou Contaminado (OLUC), que é classificado pela NBR 10004 como resíduo perigoso (ABNT, 2004).

A Lei 12.305/2010 trata da Política Nacional de Resíduos Sólidos (PNRS) e preceitua em seu Art. 33, inciso IV, a obrigatoriedade da gestão dos resíduos sólidos, incluindo o OLUC, bem como suas embalagens, que devem integrar o sistema de logística reversa. Em linhas gerais, esta lei objetiva à redução de custos na fabricação de novos produtos, bem como, a diminuição da extração de matéria-prima virgem do meio ambiente (Brasil, 2010). Quando o ciclo de vida desses produtos chega ao fim, eles são reinseridos mais uma vez na cadeia de consumo, agregando valores econômicos, sociais e ambientais, firmando o tripé da sustentabilidade ou triple bottom line (Leite, 2009; Barbieri et al., 2010).

O OLUC é derivado do petróleo, sendo altamente tóxico e contendo aditivos químicos que causam impactos no meio ambiente, levando aproximadamente 300 anos para se degradar na natureza, pois não possui característica biodegradável (Willing, 2001; Silveira, Caland \& Moura 2006; Gusmão, Fraga \& Dias, 2013). O descarte incorreto de apenas 1 litro de óleo lubrificante por dia lançado em solo ou em cursos de água é equivalente ao esgoto doméstico de 40 mil habitantes (APROMAC, 2005).

A Resolução de $\mathrm{n}^{\circ}$ 362, do Conselho Nacional do Meio Ambiente (CONAMA), proíbe o uso de aterro sanitário para disposição final do OLUC. Assim, o resíduo deverá ser recolhido, coletado e ter uma destinação final de modo que não cause danos ambientais e propicie a máxima recuperação dos constituintes nele contidos. OLUC é fonte de óleo lubrificante básico $(80 \%$ a $85 \%$ de óleo básico), que é um recurso caro e não renovável, sendo economicamente relevante que seja coletado e recuperado (Brasil, 2005). A destinação final adequada é o processo de rerrefino, que é de alto desempenho técnico, com baixo índice de rejeitos e garante uma qualidade similar ao do produto novo (Leite, 2009).

O desenvolvimento para a sociedade tem extrema relevância, contudo, deve ter limites e considerar a relação da economia com os elementos ecossistêmicos. Além disso, não se pode olvidar que o caput do Art. 225 da Constituição Federal (CF/1988) cita expressamente o princípio da solidariedade intergeracional, bem como o princípio da prevenção ao impor ao poder público e à coletividade o dever de defender e preservar o meio ambiente para presentes e futuras gerações, 
para que estas últimas também possam usufruir de forma sustentável dos recursos naturais (Brasil, 1988; Milaré, 2011; Antunes, 2014).

Fazer cumprir os princípios ambientais da Carta Magna não é apenas um dever jurídico, mas também ético, haja vista o direito de viver em um ambiente ecologicamente equilibrado compõe o rol dos direitos fundamentais que sustentam a dignidade humana, trata-se de um reflexo do primeiro princípio positivado na Declaração de Estocolmo de 1972, na Conferência das Nações Unidas sobre o Meio Ambiente, vez que ambos os documentos destacam a sadia qualidade de vida, o bem-estar, a melhoria de vida, a dignidade da pessoa humana, o meio ambiente equilibrado, a proteção, a responsabilidade compartilhada e o respeito para com as presentes e futuras gerações (Botelho, 2016).

No atual contexto, em que discussões sobre responsabilidade socioambiental, aquecimento global e desenvolvimento sustentável ganham espaço no cenário mundial, a presente pesquisa tem como objetivo identificar experiências envolvendo o gerenciamento do resíduo do óleo lubrificante usado ou contaminado conjugado com os aspectos ambientais, sociais e econômicos.

Diante dos argumentos supracitados, o presente artigo objetiva analisar a importância econômica e ambiental do processo de rerrefino do óleo lubrificante usado ou contaminado, bem como, debater o seu atual cenário, além de se debruçar na pergunta: como o processo de rerrefino do óleo lubrificante usado ou contaminado tem contribuído para a economia, sociedade e meio ambiente?

\section{MÉTODO}

O presente estudo, de cunho qualitativo e de natureza exploratória, trata de uma Revisão Sistemática da Literatura, realizada no mês de junho de 2021, a partir do resgate de artigos científicos publicados entre 2005 e 2020 nas seguintes bases de dados: Scopus, Scielo e Google Scholar. Ressalta-se que esse recorte temporal se baseia na data da criação da Resolução $\mathrm{n}^{\circ}$ 362/2005 do CONAMA, que proíbe o uso de aterro sanitário para disposição final do OLUC e estabelece que o melhor destino para este resíduo perigoso é a reciclagem, por meio do sistema de rerrefino (Brasil, 2005). Os termos indexadores utilizados para a busca dos estudos foram: "lubricating oil"; re-refinig; "sustainability tripod"; "rerrefino"; e "tripé da sustentabilidade", os quais foram interligados pelo conectivo $O R$.

O delineamento da metodologia se baseou nas seguintes recomendações científicas: a) definição da problemática e proposta de revisão; b) elaboração do formulário de registro; c) definição das equações de pesquisa (descritores e combinações) e identificação das fontes; d) âmbito da pesquisa (tipo de material e período); d) critérios de inclusão e exclusão; e) identificação, avaliação da qualidade e seleção de estudo primário; f) extração de dados, análise e síntese dos resultados (De-la-torre-ugarte-guanilo, Takahashi \& Bertolozzi, 2011).

Os critérios de inclusão utilizados foram: artigos de conhecimento teórico-empírico, de domínio nacional e internacional e relacionados ao gerenciamento de resíduos de óleo lubrificante usado ou contaminado. Já os critérios de exclusão foram: artigos de revisão, repetidos e que não estão no escopo da pesquisa. Tais critérios visaram regatar experiências que respondessem a seguinte pergunta norteadora: como o processo de rerrefino do óleo lubrificante usado ou contaminado tem contribuído para a economia, sociedade e meio ambiente?

O resultado da busca nas bases acadêmicas identificou 156 artigos. A seleção dos estudos se iniciou com a eliminação de 72 trabalhos duplicados, restando assim 84 artigos. Na sequência foram descartados 25 trabalhos teóricos, apresentados em congressos, casos de ensino, ensaios teóricos, restando 59 artigos para apreciação e análise. Posteriormente, foi realizada a leitura na íntegra dos trabalhos restantes para avaliar a aderência com o escopo proposto neste estudo. Assim, foram selecionadas 16 experiências, as quais foram submetidas na presente revisão (Figura 1). 


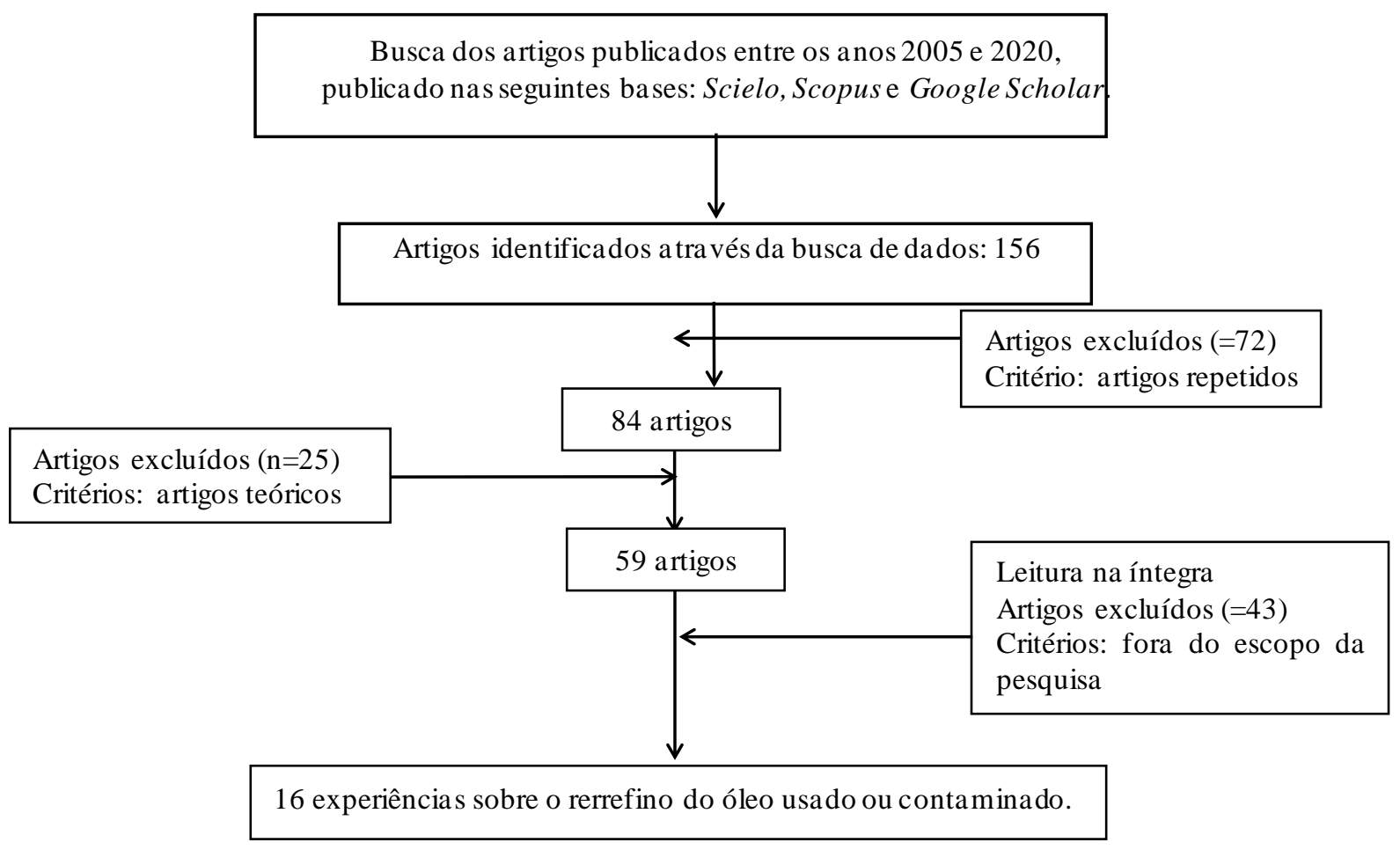

Figura 1. Procedimentos de busca de artigos nas bases acadêmicas e critérios de exclusão. Fonte: Elaborado pelos autores (2021).

\section{RESULTADOS E DISCUSSÕES}

O gerenciamento do óleo lubrificante tem sido alvo de diversos estudos pela comunidade científica, visto que o resíduo, classificado como perigoso, deve ser corretamente manejado, armazenado e destinado à coleta e ao rerrefino, a fim de evitar danos decorrentes de sua disposição incorreta (APROMAC, 2005). Abaixo, o Quadro 1 ilustra as informações gerais dos estudos selecionados, publicados nas duas últimas décadas no tocante ao gerenciamento do óleo lubrificante, o processo de rerrefino, bem como suas contribuições para a economia, meio ambiente e sociedade. Depreende-se que as metodologias mais utilizadas foram de cunho qualitativo, de caráter exploratório e o público alvo das pesquisas foram gestores e proprietários de estabelecimentos que oferecem o serviço de troca de óleo automotivo. Além disso, observa-se que, no Brasil, a cidade de Lençóis Paulista, localizada na região centro-oeste de São Paulo, apresenta resultados mais satisfatórios em relação ao desempenho da logística reversa do OLUC, isso se deve ao fato de que nessa região está sediada a matriz de uma das maiores empresas desse segmento, a Lwart Lubrificantes, que atualmente domina o mercado de rerrefino no país. 


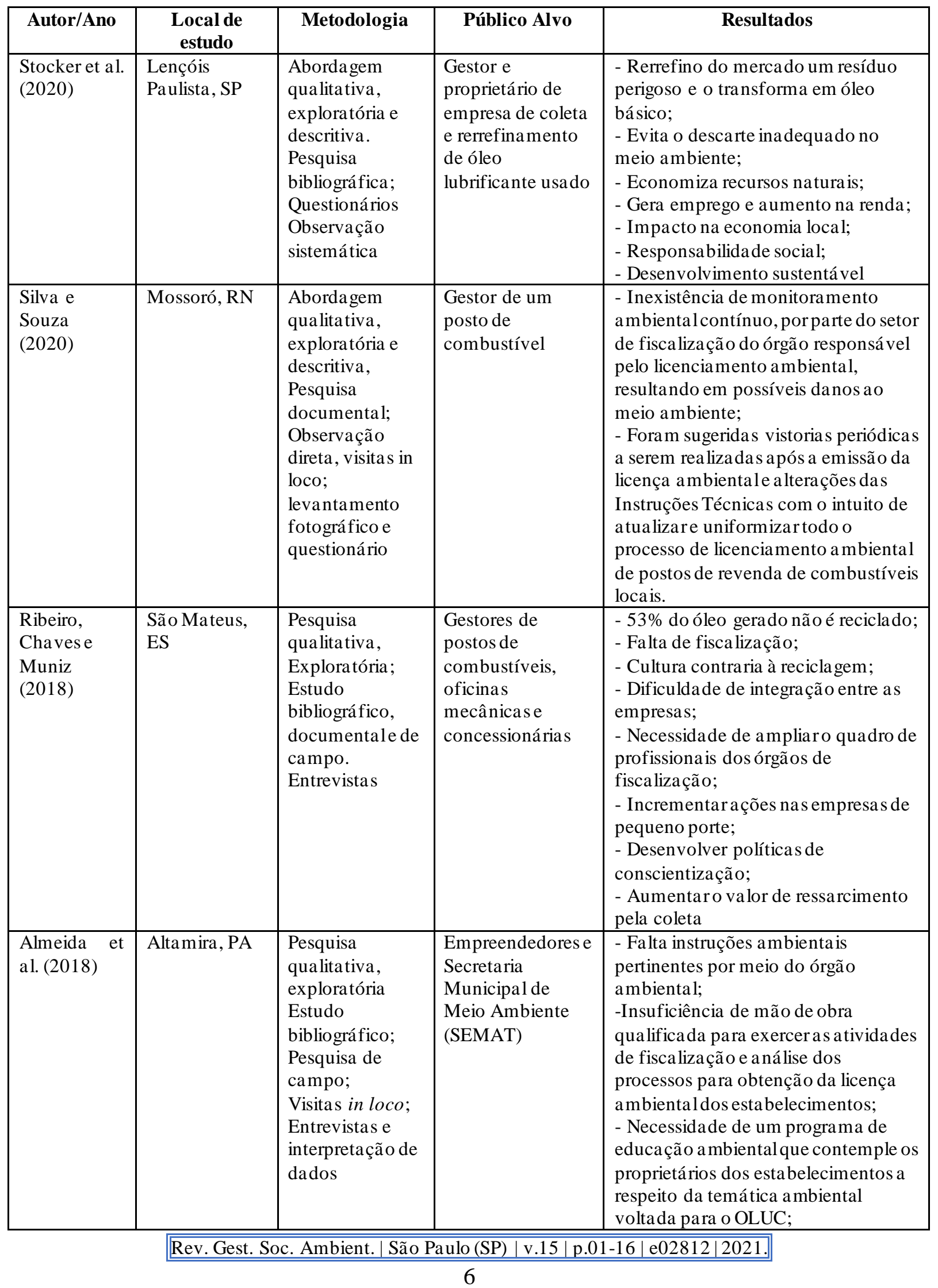




\begin{tabular}{|c|c|c|c|c|}
\hline & & & & $\begin{array}{l}\text { - Necessidade de fiscalização por } \\
\text { parte do órgão a mbientale } \\
\text { compromisso de todos os atores } \\
\text { envolvidos: consumidor, proprietário } \\
\text { do estabelecimento e profissional } \\
\text { contratado para auxiliar no processo } \\
\text { de licenciamento }\end{array}$ \\
\hline $\begin{array}{l}\text { Mota e } \\
\text { Figueiredo } \\
(2017)\end{array}$ & Palmas,TO & $\begin{array}{l}\text { Pesquisa } \\
\text { qualitativa; } \\
\text { Estudo } \\
\text { bibliográfico; } \\
\text { Estudo de caso; } \\
\text { Entrevistas }\end{array}$ & $\begin{array}{l}\text { Gestores de sete } \\
\text { oficinas } \\
\text { mecânicas }\end{array}$ & $\begin{array}{l}\text { - O processo de rerrefino é primordial } \\
\text { para a economia do Bra sil; } \\
\text { - Logística reversa é pouco } \\
\text { conhecida; } \\
\text { - Em nenhuma das oficinas } \\
\text { mecânicas é realizado o descarte } \\
\text { adequado do OLUC; } \\
\text { - Ausência de informação e } \\
\text { fiscalização }\end{array}$ \\
\hline $\begin{array}{l}\text { Oliveira et } \\
\text { al. (2017) }\end{array}$ & Varginha, MG & $\begin{array}{l}\text { Pesquisa } \\
\text { qualitativa, } \\
\text { exploratória; } \\
\text { Método } \\
\text { hipotético- } \\
\text { dedutivo; } \\
\text { Estudo } \\
\text { bibliográfico; } \\
\text { Pesquisa de } \\
\text { campo; } \\
\text { Entrevistas } \\
\end{array}$ & $\begin{array}{l}1 \text { analista do setor } \\
\text { de processos e } 1 \\
\text { analista do setor } \\
\text { de logística, } \\
\text { pertencentes a } \\
\text { uma empresa de } \\
\text { rerrefino de } \\
\text { OLUC }\end{array}$ & $\begin{array}{l}\text { - A logística é atividade } \\
\text { imprescindível para manutenção da } \\
\text { empresa; } \\
\text { - A coleta é o maior desafio para a } \\
\text { empresa devido a os custos; } \\
\text { - Mercado de rerrefino está a quecido, } \\
\text { devido a o aumento da frota de } \\
\text { veículos, pressões para rea lização do } \\
\text { rerrefino e das relações de } \\
\text { concorrência entre empresas do setor. }\end{array}$ \\
\hline $\begin{array}{l}\text { Tristão, } \\
\text { Tristão e } \\
\text { Frederico } \\
(2017)\end{array}$ & São Paulo, SP & $\begin{array}{l}\text { Pesquisa } \\
\text { bibliográfica }\end{array}$ & $\begin{array}{l}\text { Estudo } \\
\text { documental } \\
\text { envolvendo } \\
\text { conceitos de ciclo } \\
\text { de vida do } \\
\text { produto e } \\
\text { logística reversa } \\
\text { do OLUC }\end{array}$ & $\begin{array}{l}\text { - Dimensão geográfica do Bra sil } \\
\text { dificulta a coleta do OLUC; } \\
\text { - Deficiências sistêmicas e } \\
\text { necessida de de aprimoramento do } \\
\text { sistema de logística reversa no } \\
\text { processo de reciclagem. } \\
\text { - Agrega ção de va lor a o produto; } \\
\text { - Minimização de impactos } \\
\text { ambientais. }\end{array}$ \\
\hline $\begin{array}{l}\text { Lima e } \\
\text { Viana } \\
(2016)\end{array}$ & São Paulo, SP & $\begin{array}{l}\text { Pesquisa } \\
\text { qualitativa; } \\
\text { Estudo de caso; } \\
\text { Visitas in loco; } \\
\text { Entrevistas }\end{array}$ & $\begin{array}{l}\text { Gestor de uma } \\
\text { oficina mecânica }\end{array}$ & $\begin{array}{l}\text { - A taxa de a proveitamento pela } \\
\text { reutilização de materiais ou mesmo a } \\
\text { recicla gem é muito baixa; } \\
\text { - Inutilização dos equipamentos de } \\
\text { proteção individual na stapas de } \\
\text { coleta e manuseio, que pode acarretar } \\
\text { em problemas na saúde dos } \\
\text { trabalhadores. } \\
\text { - Armazenamento de resíduos } \\
\text { inadequado; } \\
\text { - Deve aprimoraro gerenciamento do } \\
\text { óleo usado }\end{array}$ \\
\hline $\begin{array}{l}\text { Nascimento } \\
\text { et al. (2016) }\end{array}$ & $\begin{array}{l}\text { Campina } \\
\text { Grande, PB }\end{array}$ & $\begin{array}{l}\text { Pesquisa } \\
\text { qualitativa, } \\
\text { exploratória e } \\
\text { descritiva; } \\
\text { Estudo } \\
\text { bibliográfico; } \\
\text { Estudo de } \\
\text { campo; } \\
\text { Questionários }\end{array}$ & $\begin{array}{l}\text { Gestores de } \\
\text { postos de } \\
\text { combustíveis }\end{array}$ & $\begin{array}{l}\text { - Mais de } 50 \% \text {, considera ram possuir } \\
\text { nenhum conhecimento ou } \\
\text { conhecimento insuficiente sobre a } \\
\text { PNRS e a LR; } \\
\text { - 48,57\% ainda desconhecem o } \\
\text { importante pa pel que a Controla doria } \\
\text { exerce no ambiente empresarial; } \\
\text { - 65,71\% afirmaram possuir } \\
\text { conhecimento sobre o gerenciamento } \\
\text { dos resíduos sólidos; } \\
\text { - } 11,43 \% \text { jogados em lixões ou } \\
\text { lançados em locais ina dequados e }\end{array}$ \\
\hline
\end{tabular}




\begin{tabular}{|c|c|c|c|c|}
\hline & & & & sem nenhum tratamento \\
\hline $\begin{array}{l}\text { Capello et } \\
\text { al. }(2015)\end{array}$ & $\begin{array}{l}\text { Florianópolis, } \\
\text { SC e } \\
\text { Lençóis } \\
\text { Paulista, SP }\end{array}$ & $\begin{array}{l}\text { Pesquisa } \\
\text { qua litativa, } \\
\text { exploratória e } \\
\text { descritiva; } \\
\text { Estudo } \\
\text { bibliográfico; } \\
\text { Observação } \\
\text { sistemática; } \\
\text { Questionários }\end{array}$ & $\begin{array}{l}\text { Gestores de duas } \\
\text { empresas } \\
\text { distintas: uma } \\
\text { concessionária de } \\
\text { veículos, geradora } \\
\text { de resíduo e outra } \\
\text { coletadora e } \\
\text { rerrefinadora do } \\
\text { resíduo do OLUC }\end{array}$ & $\begin{array}{l}\text { - Economia gerada pelo } \\
\text { reaproveita mento do óleo; } \\
\text { - Redução da poluição; } \\
\text { - Redução da geração de resíduo; } \\
\text { - Redução na extração e importação } \\
\text { de petróleo; } \\
\text { - Agrega valor à economia; } \\
\text { - Necessidade de difundir a ideia do } \\
\text { rerrefino. }\end{array}$ \\
\hline $\begin{array}{l}\text { Demajorovic } \\
\text { e Sencovic } \\
(2015)\end{array}$ & São Paulo, SP & $\begin{array}{l}\text { Pesquisa } \\
\text { qualitativa, } \\
\text { explora tória; } \\
\text { Estudo } \\
\text { bibliográfico; } \\
\text { Entrevistas } \\
\text { semiestrutura da } \\
\text { s; } \\
\text { Análise de } \\
\text { conteúdo }\end{array}$ & $\begin{array}{l}\text { Representantes da } \\
\text { cadeia de óleo } \\
\text { lubrificantes e } \\
\text { embalagens }\end{array}$ & $\begin{array}{l}\text { - Necessidade de avanços para } \\
\text { ampliar a logística reversa; } \\
\text { - Ausência de fiscalização mais } \\
\text { efetiva; } \\
\text { - Ausência de incentivos fiscais e } \\
\text { melhoria nos processos de coleta, } \\
\text { armazenamento e transporte }\end{array}$ \\
\hline $\begin{array}{l}\text { Martine e } \\
\text { Alves (2015) }\end{array}$ & São Paulo, SP & $\begin{array}{l}\text { Pesquisa } \\
\text { qualitativa, } \\
\text { exploratória; } \\
\text { Estudo } \\
\text { bibliográfico e } \\
\text { documental }\end{array}$ & $\begin{array}{l}\text { Profissionais } \\
\text { responsá veis pelo } \\
\text { estudo estrutural } \\
\text { da crise } \\
\text { ambiental, } \\
\text { desenvolvimento } \\
\text { social, população } \\
\text { e meio ambiente }\end{array}$ & $\begin{array}{l}\text { - Nos últimos } 70 \text { anos, o sistema de } \\
\text { produção explorou os recursos } \\
\text { naturais renová veis e não renová veis } \\
\text { cm intensidade; } \\
\text { - As atividades humanas } \\
\text { ultra pa ssaram os seus limites } \\
\text { econômicos planetários; } \\
\text { - O crescimento quantitativo da } \\
\text { economia deve ficar dentro das } \\
\text { fronteira slanetárias, sem } \\
\text { comprometer a bioca pacidade da } \\
\text { Terra e a biodiversidade das espécies. }\end{array}$ \\
\hline $\begin{array}{l}\text { Kapustina et } \\
\text { al. (2014) }\end{array}$ & Finlândia & $\begin{array}{l}\text { Abordagem de } \\
\text { pensamento } \\
\text { sistêmico para } \\
\text { identificar } \\
\text { principais } \\
\text { componentes do } \\
\text { sistema e } \\
\text { mostrar } \\
\text { interconexões } \\
\end{array}$ & $\begin{array}{l}\text { Profissionais da } \\
\text { tecnologia } \\
\text { ambiental }\end{array}$ & $\begin{array}{l}\text { - Aumento de desempenho } \\
\text { - Taxa de recolhimento de óleo usado } \\
\text { aumentou mais de } 30 \% \text { durante os } \\
\text { últimos } 6 \text { anos; } \\
\text { - Desempenho ambientalmelhorou } \\
\text { mais de } 70 \% \text { nos últimos } 6 \text { anos; } \\
\text { devido a o aumento da taxa de } \\
\text { recuperação de materiais. }\end{array}$ \\
\hline $\begin{array}{l}\text { Grice et al. } \\
(2014)\end{array}$ & EUA & $\begin{array}{l}\text { Comparara } \\
\text { pegada } \\
\text { de carbono da } \\
\text { produção de } \\
\text { óleo } \\
\text { rerrefinado com } \\
\text { o } \\
\text { óleo de primeiro } \\
\text { refino }\end{array}$ & $\begin{array}{l}\text { Safety-Kleen } \\
\text { Systems, maior } \\
\text { produtor de óleo } \\
\text { rerrefinado da } \\
\text { América do Norte }\end{array}$ & $\begin{array}{l}\text { - Em todos os cenários estudados o } \\
\text { rerrefino apresentou menos de } \\
50 \% \text { das emissões comparado a ó óleo } \\
\text { de primeiro refino }\end{array}$ \\
\hline $\begin{array}{l}\text { Pires e } \\
\text { Marinho } \\
(2012)\end{array}$ & Portugal & $\begin{array}{l}\text { Pesquisa sobre a } \\
\text { análise da } \\
\text { pegada de } \\
\text { carbono } \\
\text { utilizando o } \\
\text { software } \\
\text { Umberto } 5,5 \\
\text { com base em } \\
\text { conceitos de } \\
\text { a valiação do } \\
\end{array}$ & $\begin{array}{l}\text { Painel } \\
\text { Intergovernament } \\
\text { al sobre } \\
\text { Mudanças } \\
\text { Climáticas (IPCC, } \\
\text { 2007) }\end{array}$ & $\begin{array}{l}\text { - O gerenciamento do óleo usado } \\
\text { pode contribuir para a redução da } \\
\text { pegada de carbono; } \\
\text { - Melhoria percebida com o aumento } \\
\text { do uso de óleo residual tra tado pa ra a } \\
\text { produção de argila expandida é } \\
\text { melhor do que a opção de refino; } \\
\text { - Maior emissão de GEE durante a } \\
\text { combustão, da recuperação do óleo } \\
\text { para recuperação de energia para }\end{array}$ \\
\hline
\end{tabular}




\begin{tabular}{|c|c|c|c|c|}
\hline & & $\begin{array}{l}\text { ciclo de vida } \\
\text { com respeito às } \\
\text { normas } \\
\text { internacionais } \\
\text { (ISO) }\end{array}$ & & produzir eletricidade \\
\hline $\begin{array}{l}\text { Hsu e Liu } \\
(2010)\end{array}$ & Taiwan, China & $\begin{array}{l}\text { Pesquisa } \\
\text { realizada com o } \\
\text { Método Briefing } \\
\text { de AHP, } \\
\text { Utilização do } \\
\text { processo de } \\
\text { hierarquia } \\
\text { analítica para } \\
\text { selecionar, } \\
\text { analisare } \\
\text { compararas } \\
\text { tecnologias } \\
\text { regenerativas do } \\
\text { óleo }\end{array}$ & $\begin{array}{l}\text { Especialistas e } \\
\text { estudiosos da área } \\
\text { de tecnologia e } \\
\text { reciclagem de } \\
\text { óleo residual }\end{array}$ & $\begin{array}{l}\text { - Existe um sistema de recicla gem } \\
\text { subterrânea, que pode equilibrar o } \\
\text { processamento e o destino do óleo } \\
\text { lubrificante; } \\
\text { - A proporção de rerrefino do óleo } \\
\text { usado deve ser melhorada; } \\
\text { - Sistema de cooperaçãa, fa vorecerá } \\
\text { lucros com a recicla gem do óleo; } \\
\text { - Geração de emprego com a } \\
\text { expansão das estações de recicla gem; } \\
\text { - Minimização de custos para manter } \\
\text { o meio ambiente e lidar com a } \\
\text { poluição. }\end{array}$ \\
\hline
\end{tabular}

Quadro 1. Artigos seleciona dos sobre análise do gerencia mento de resíduos de óleo lubrificante usado ou conta minado. Fonte: Elabora do pelos autores (2021).

Com o avanço do número de veículos e do alto consumo de óleo lubrificante automotivo, surge a necessidade de investigar a gestão dos resíduos gerados por esta atividade, pois, sabe-se que, após o uso em automóveis, máquinas e motores, este se deteriora e perde eficiência em razão de misturas que contêm frações de metais e aditivos. Porém, o óleo lubrificante usado ou contaminado é classificado como resíduo perigoso, devendo ser obedecidas às exigências legais quanto a sua coleta, tratamento e disposição final (ABNT, 2004). O OLUC não possui característica biodegradável, leva dezenas de anos para desaparecer na natureza, onde um litro de óleo usado descartado de forma inadequada pode contaminar um milhão de litros de água, não pode ser queimado, pois, emite gases e substâncias tóxicas, além de comprometer à saúde humana. Portanto, a fim de evitar esses impactos negativos, deve ser coletado e reciclado, por meio do processo de rerrefino (Willing, 2001; Hsu \& Liu, 2011; Ribeiro, Chaves \& Muniz, 2015).

A melhor maneira de reduzir a circulação desse resíduo perigoso é submeter ao processo físico-químico do rerrefino, com a finalidade de recuperar as características que são perdidas com seu uso, transformando o óleo em nova matéria-prima, a qual será empregada para produção de novo óleo lubrificante. Além do aspecto ambiental, destaca-se a viabilidade econômica, pois obtém a partir da regeneração do óleo, a redução da necessidade de extração e importação de petróleo, fonte de energia finita e de alto custo (Capello, Paula, Pradella \& Grando, 2015).

Nos últimos 70 anos, a atividade industrial explorou os recursos naturais renováveis e não renováveis com intensidade e os ecossistemas estão sendo alterados e destruídos. O seguimento da indústria automotiva é uma atividade altamente poluidora que acarreta a geração de um volume considerável de resíduos sólidos, em razão disso, deve cumprir exigências legais, com o objetivo de reduzir os danos ao meio ambiente e à saúde da população (Martine \& Alves, 2015; Amarante, 2019).

De maneira geral, as empresas têm se apropriado do conceito de sustentabilidade com a finalidade de conquistar o público consumidor, não se importando efetivamente com a esfera ambiental, mas apenas com o crescimento. A distinção entre crescimento e desenvolvimento, é que o objetivo do crescimento é apenas a geração de riqueza, não levando à igualdade, enquanto que o desenvolvimento, além de focar na produção de riquezas, tem como finalidade, distribuí-las, visando, acima de tudo, o equilíbrio e a qualidade ambiental do planeta (Amarante, 2018).

$\mathrm{O}$ atual modelo de desenvolvimento econômico tem se baseado no uso insustentável dos recursos não renováveis, no aumento da concentração de dióxido de carbono na atmosfera, na redução da biodiversidade, acidificação dos oceanos e geração de crises ambientais e sociais. A 
esfera econômica demonstra sinais de exaustão em decorrência do atual modelo hegemônico, pois não se demonstra socialmente justo e ambientalmente sustentável. O crescimento deve pautar-se no equilíbrio e ficar contido dentro das fronteiras planetárias, preservando a biocapacidade da Terra e a biodiversidade das espécies (Martine \& Alves, 2015).

Os impactos ambientais causados pelo descarte incorreto do OLUC no meio ambiente, quase sempre são irreversíveis. A coleta e a destinação final ambientalmente adequada desse produto devolve ao mercado um óleo básico com as mesmas qualidades e características do óleo original, o que torna esse modelo imprescindível para a preservação do meio ambiente e o crescimento econômico do país. O rerrefino salva um recurso natural não renovável enquanto reduz as emissões de gases de efeito estufa no ambiente, tornando-o um produto que pode ser usado de modo contínuo, diminuindo custos na produção de óleo básico (Rac \& Vencl, 2012; Capello et al., 2015; Izza et al., 2018; Stocker et al., 2020).

Grice et al. (2014), compararam a pegada de carbono no tocante à fabricação de óleo rerrefinado nos EUA, com a produção de óleo do primeiro refino, e constataram que o sistema de rerrefino apresentou 50\% menos emissões de gases de efeito estufa (GEE), em comparação ao óleo de primeiro refino. Nos estudos de Pires e Marinho (2012), realizados em Portugal, foi comparada a pegada de carbono do gerenciamento do resíduo por meio de rerrefino, recuperação energética e produção de argila expandida, tendo essa última causado menos impacto de aquecimento global, o que demonstra a necessidade de pesquisas direcionadas às coletas separadas de diferentes resíduos a fim de avaliar os impactos ambientais advindos de cada tratamento.

Mundialmente, cerca de 45 milhões de litros de lubrificante são consumidos por ano, gerando mais de 20 bilhões de litros de óleos usados. Se 50\% desse volume de resíduo gerado for devidamente coletado e destinados adequadamente, ainda restariam 10 bilhões de litros não coletados, que podem ser jogados diretamente nos subsolos, rios, mares e atmosfera, acarretando mais poluição ambiental. Os países desenvolvidos, que são os maiores consumidores do produto, vêm incorporando ações com objetivo de incentivar a prática da reciclagem do resíduo (Tristão, Tristão \& Frederico, 2017).

A Alemanha possui leis mais rigorosas no controle ambiental e é o país que mais avança em termos de coleta e rerrefino, onde $65 \%$ do óleo coletado é rerrefinado. Tanto nos EUA como na França, parte do óleo usado que atende os requisitos técnico-ambientais para a queima é coletado, recebe tratamento e é queimado em fornos de cimento e usinas termoelétricas, o que pode ser considerado desperdício de um produto nobre, já que o óleo é reutilizado apenas uma vez. $\mathrm{Na}$ Califórnia, o óleo também poderá ser destilado para utilização como óleo diesel marinho de excelente qualidade (Boughton \& Horvath, 2004; Tristão et al., 2017).

Portugal consome anualmente cerca de 100 milhões de litros de óleo lubrificante, destes, $60 \%$, poderiam ser reciclados, após o uso. No entanto, apenas $30 \%$ são recolhidos por empresas licenciadas, os restantes $30 \%$ são coletados no mercado paralelo e têm destinação final inadequada. A ineficiência da reciclagem se dá em razão da ausência de uma rede de pontos de coleta no país (Audibert, 2006; Tristão, Tristão \& Frederico, 2017). A China conta com um sistema de reciclagem subterrânea, que pode equilibrar o processamento e o destino do óleo lubrificante, o qual poderá ser utilizado em instalações de conversões em combustíveis para navios (Hsu \& Liu, 2010).

A opção pelo sistema de rerrefino do óleo usado tem sido implementada por diversos países como Bélgica, Luxemburgo, Dinamarca, Alemanha, Itália, Grécia, Holanda e Polônia. Todos esses países atingiram taxas maiores de 70\% de rerrefino (Boughton \& Horvath, 2004; Pires \& Martinho, 2012).

Estados Unidos, Japão, Portugal, França, Alemanha, Finlândia e Grécia vêm realizando investimentos na criação de sistemas de gestão do OLUC, para minimizar impactos ambientais, recuperar os recursos naturais e reduzir custos. Na Itália, a coleta é administrada pelo Consortium, uma entidade mantida conjuntamente por órgãos governamentais e empresas de petróleo e rerrefino. Os fabricantes pagam uma taxa aos responsáveis pela coleta, os quais encaminham os óleos para a 
reciclagem, combustão, rerrefino ou incineração. Esses sistemas são baseados, principalmente, em cobranças de taxas ambientais sobre o litro de óleo colocado no mercado. Destaque principal para a Finlândia, que até 2007, o resíduo do óleo era utilizado como combustível em incineradores, fornos de cimento e usinas elétricas e, após implementar o gerenciamento do óleo usado, vem apresentando avanços significativos, vez que, o percentual encaminhado à regeneração passou de 9\% em 2006 para 87\% em 2011 (Kapustina et al., 2014).

No Brasil, o consumo anual ultrapassa um bilhão de litros, dos quais são gerados cerca de 450 milhões de litros de óleos usados e apenas $25 \%$ ou cerca de 250 milhões de litros estão sendo coletados para rerrefino. Os 200 milhões restantes têm destinação desconhecida, ou seja, estão sendo dispostos de forma inadequada, condenando não só o meio ambiente, mas a saúde pública. A grande extensão geográfica do Brasil dificulta a coleta e a reciclagem, por meio do sistema de rerrefino (Tristão, Tristão \& Frederico, 2017; Mota \& Figueiredo, 2017).

O Brasil ocupa o quinto lugar no ranking mundial como gerador de óleo usado e levando em consideração os impactos advindos do gerenciamento incorreto do OLUC à saúde pública e à degradação ambiental, a sua destinação é alvo de regulamentação específica em várias esferas (Brasil, 2019). A resolução de no 362/2005 do CONAMA preceitua a coleta do OLUC e a reciclagem por meio do processo de rerrefino, sendo a mais eficiente do ponto de vista tecnológico, atendendo os princípios dos 3Rs da Agenda 21 (Reduzir, Reutilizar e Reciclar) (Brasil, 2005). O rerrefino é altamente benéfico para a economia e o meio ambiente, prolonga a vida útil do petróleo, contribuindo para reduzir o desperdício, a geração de resíduos e a necessid ade de extração e importação de um recurso tão valioso e de alto custo (Capello et al., 2015; Izza et al., 2018).

Estudos realizados com gestores e representantes da cadeia de óleo lubrificante, nas cidades de Florianópolis, em Santa Catarina e Lençóis Paulista, em São Paulo, apontam que a regeneração para óleos usados representa uma real solução para a minimização tanto de custos diretos das empresas quanto dos passivos ambientais gerados por suas atividades produtivas, sendo rentável e ecologicamente correta. No entanto, fazem-se necessários a fiscalização mais efetiva, recursos humanos, incentivos fiscais e melhoria nos processos de coleta e reciclagem para potencializar os benefícios econômicos, ambientais e sociais desta atividade no país (Capello et al., 2015; Demajorovic \& Sencovici, 2015; Almeida et al., 2018).

São inúmeros os benefícios da reciclagem do óleo usado que refletem na economia de recursos naturais, na geração de empregos e aumento de renda. A reciclagem agrega valor à economia, reduzindo a extração e importação de petróleo, bem como, estabiliza o consumo e auxilia na descarbonização da economia. Apesar da inexistência de incentivos governamentais, altos custos com logística no tocante à entrega de óleo rerrefinado e à coleta do OLUC, a reciclagem do óleo lubrificante usado ainda reúne benefícios de ordem econômica e ambientais (Hsu \& Liu, 2010; Capello et al., 2015; Oliveira et al., 2017; Stocker et al., 2020).

Nas pesquisas realizadas com gestores e proprietários de postos de combustíveis e oficinas mecânicas, na cidade de Campina Grande/PB, Nascimento et al. (2016) identificaram que mais de 50\% dos entrevistados não possuíam nenhum conhecimento sobre a Lei 12.305/2010 (PNRS) e a logística reversa (Brasil, 2010). Em nenhuma das oficinas mecânicas avaliadas se realiza o descarte e o manejo adequado do OLUC.

Nos municípios brasileiros, as oficinas são empreendimentos que oferecem serviços básicos e influenciam diretamente a economia local. No entanto, o problema do descarte incorreto de resíduos está situado nas oficinas menores, visto que na maioria delas não há preocupação ambiental, pois, muitas vezes, os proprietários não tem como comprar ou adaptar tanques adequados em seu estabelecimento e fazem uso de bombonas e tambores que têm valores mais atrativos, este último merece cuidados especiais, pois pode ser facilmente amassado e têm grandes chances de enferrujar. Esses recipientes devem estar acondicionados em uma bacia de contenção, pois, em caso de acidente, evitará que o resíduo se espalhe. Portanto, nesses estabelecimentos ocorre a ausência de uma gestão ambiental eficiente que amplie os recursos humanos, bem como, 
uma maior fiscalização por parte dos órgãos ambientais (Lima \& Viana, 2016; Mota \& Figueiredo, 2017; Almeida et al., 2018). Silva e Souza (2020), pontuam que o armazenamento de resíduos perigosos deve ser em recipientes resistentes a possíveis vazamentos, devendo ser coletados e transportados por empresa devidamente licenciada para essa atividade. Para Hsu e Liu (2011), o impacto ambiental deve ser considerado como o aspecto mais relevante na armazenagem e reciclagem do óleo usado.

Em que pese sua relevância estratégica no mercado econômico, não se pode olvidar que os óleos lubrificantes usados são classificados como resíduos perigosos e devem ser manejados e descartados de maneira ambientalmente correta para evitar a contaminação do ar, da água, do solo e de alimentos. O OLUC causa impactos à saúde dos trabalhadores ligados à sua manipulação, problemas respiratórios, doenças degenerativas, má formação do feto e câncer, o que caracteriza um fator indutor de pobreza, sobrecarga do sistema de seguridade social, do sistema de saúde, nos custos de remediação ambiental, na perda da arrecadação e no desperdício de recurso não renovável (Amarante, 2018).

No Brasil, em 2019, foram comercializados 1.367.528.000 litros de óleo lubrificante, sendo devidamente coletados 489.419.000 litros. Depreende-se, portanto, que, apenas 35,78\% de todo óleo comercializado foi destinado à coleta. $\mathrm{O}$ descarte inadequado no solo e nos cursos de água causam danos ambientais, muitas vezes irreversíveis. É preciso implementar a prática da logística reversa e cumprir a meta de coleta estabelecida pelo Ministério do Meio Ambiente (MMA), que atualmente prevê novos índices para a coleta mínima de óleo lubrificante no Brasil para o quadriênio 2020/2023, que deve chegar ao percentual de 47,5\% até 2023, conforme a Portaria Interministerial no 475 de 2019 (Brasil, 2019).

\section{CONSIDERAÇÕES FINAIS}

Em resposta à pergunta norteadora, objeto dessa análise - Como o processo de rerrefino do óleo lubrificante usado ou contaminado tem contribuído para a economia, sociedade e o meio ambiente? - os estudos apontaram diversos benefícios proporcionados pelo sistema de rerrefino do óleo lubrificante usado interligados com o desenvolvimento sustentável, refletindo nas esferas econômica, social e ambiental, uma vez que une economia com preservação ambiental, contribuindo, ainda, com o enfrentamento às mudanças climáticas, reduzindo as emissões de gases de efeito estufa.

O processo de rerrefino no Brasil e em muitos países vem se apresentando como uma interessante opção para a gestão de resíduos de óleos lubrificantes usados, nos aspectos técnicos, econômicos e ambientais, vez que agrega valor econômico a um resíduo que é potencialmente prejudicial ao meio ambiente e à saúde pública.

O resíduo do óleo lubrificante usado possui hidrocarbonetos que podem ser recuperados, o que significa um ganho econômico potencial, visto que, o óleo básico retirado pode receber aditivos e retomar às propriedades e características de óleo lubrificante. O processo de rerrefino é essencial para reduzir a compra de petróleo, estabilizar o consumo e auxiliar na descarbonização da economia, sendo importante para a manutenção da soberania do país, na política nacional de abastecimento de derivados de petróleo.

Para o meio ambiente, os benefícios são inúmeros, vez que sua coleta e reciclagem economiza energia, possibilita o uso de recursos naturais pelo tempo mais longo possível, reduz desperdícios e a emissão de GEE lançados no meio ambiente. A nível social gera emprego e renda no setor, alinhando-se com os aspectos da tão almejada economia circular.

No Brasil, existe legislação que disciplina a destinação ambientalmente correta desse resíduo, por meio do processo de coleta e tratamento, proporcionando a máxima recuperação dos constituintes nele contidos, conforme dispõe a Resolução Conama $n^{\circ}$ 362/2005. Na maioria dos 
estabelecimentos pesquisados ficou constatada a falta de informação sobre o gerenciamento do óleo usado, a ausência de fiscalização e a necessidade de capacitação dos agentes de licenciamento ambiental. Além disso, em razão da vasta extensão geográfica, são diversos os desafios enfrentados para ampliar o sistema de rerrefino. Todavia, não obstante os avanços legais e a implementação já alcançada no setor, ainda há muito a se fazer, principalmente no tocante à coleta, que passa por questões culturais e padece pela falta de uma estrutura nacional acarretando uma menor eficiência no envio do material para reciclagem.

Por fim, a partir desse estudo, foi possível identificar os impactos que o gerenciamento incorreto do OLUC pode causar e pontuar os benefícios para a conservação ambiental, justiça social e o crescimento econômico, que são proporcionados pela destinação final ambientalmente adequada dada ao resíduo, por meio do sistema de rerrefino.

A problemática abordada neste artigo almeja levantar um debate sobre o tema, colaborando dessa forma, com futuros estudos, contribuindo com a literatura científica, auxiliando na ampliação de experiências sobre o processo de rerrefino do óleo lubrificante usado ou contaminado. No entanto, a temática não se esgota, e para maior aprofundamento, sugere-se novos estudos que abranjam um maior número de bases dados.

\section{REFERÊNCIAS}

ABNT, Associação Brasileira de Normas Técnicas (2004). NBR 10004, Resíduos Sólidos: Classificação.

Almeida, J. M., Lisboa, A. P., Silva, C. W. \& Paes, G. K. A. A. (2018). Análise da gestão ambiental do óleo lubrificante usado ou contaminado (OLUC) no município de Altamira-PA. Revista Delos: Desarrollo Local Sostenible, 11(32).

Amarante, I. C. S. (2019). Os impactos na saúde humana e no meio ambiente decorrentes do manejo e descarte indevidos dos resíduos de óleos lubrificantes. Revista Jus Navigandi.

Antunes, P. B. (2014). Direito Ambiental. (16 ed.) São Paulo: Atlas.

APROMAC. Associação de Proteção ao Meio Ambiente de Cianorte (2005). Relatório de Gestão no Conselho Nacional de Meio Ambiente - CONAMA: justificativa da opção pelo rerrefino. Cianorte: APROMAC.

Audibert, F. (2006). Waste engine olis: Rerrefining and energy recovery. Elsevier, Oxford.

Barbieri, J. C., Vasconcelos, I. F. G., Andreassi, T. \& Vasconcelos, F.C. (2010). Inovação e sustentabilidade: novos modelos e proposições. Revista de Administração de Empresas, 50(2), 146154.

Botelho, T. R. (2016). O reconhecimento do meio ambiente ecologicamente equilibrado como direito humano e fundamental. Publica Direito. Recuperado em 19 de out. 2021. <http://www.publicadireito.com.br/artigos/?cod=ab73f542b6d60c4d >.

Boughton, B. \& Horvath, A. (2004). Environmental Assessment of Used Oil.Management Methods. Environmental Science \& Technology, 38(2), 353-358. 
Brasil. Agência Nacional do Petróleo Gás Natural e Biocombustíveis (2019). Painel Dinâmico do Mercado Brasileiro de Lubrificantes, Recuperado em 19 de out. 2021, de: $<$ http://www.anp.gov.br/lubrificantes/5610-painel-dinamico-do-mercado-brasileiro-delubrificantes>

Brasil. Conselho Nacional do Meio Ambiente. Resolução $n^{o}$ 362, de 23 de junho de 2005 (2005). Dispõe sobre o recolhimento, coleta e destinação final de óleo lubrificante usado ou contaminado.

Brasil (1988). Constituição da República Federativa do Brasil. Brasília, Senado Federal.

Brasil. Lei $n^{o}$ 12.305, de 2 de agosto de 2010 (2010). Institui a Política Nacional de Resíduos Sólidos; altera a Lei no 9.605, de 12 de fevereiro de 1998; e dá outras providências.

Brasil. Ministério de Minas e Energia. Portaria Interministerial $n^{\circ} 475$, de 19 de dezembro de 2019 (2019). Recuperado em 19 de out. 2021. <https://www.gov.br/mme/pt-br/acesso-ainformacao/legislacao/portarias-interministeriais/portaria_interministerial_mme-mma_n_4752019>.

Brasil. Ministério do Meio Ambiente. Brasil participa da COP26, conferência para discutir meio ambiente e clima (2021). Recuperado em 19 de out. 2021. <https://www.gov.br/ptbr/noticias/meio-ambiente-e-clima/2021/10/brasil-participa-da-cop26-conferencia-para-discutirmeio-ambiente-e-clima>.

Capello, A., Paula, A. M. A., Pradella, A. M. \& Grando, M. L. (2015). Reaproveitamento do óleo lubrificante: uma solução para o futuro. Revista Tecnológica, 3(2), 268-283.

De-la-Torre-Ugarte, M. C., Takahashi, R. F., \& Bertolozzi, M. R. (2011). Revisão sistemática: noções gerais. Revista da Escola de Enfermagem da USP, 45(5), 1260-1266.

Demajorovic, J. \& Sencovici, L. (2015). Entraves e perspectivas para a logística reversa do óleo lubrificante e suas embalagens. Journal of Environmental Management and Sustainability - JEMS, $4(2)$.

Gusmão, J. S., Fraga, M. S. \& Dias, J. S. (2013). A logística reversa aplicada aos óleos lubrificantes usados ou contaminados produzidos nos postos de combustíveis da cidade de Boa Vista-RR. Caderno de Ciências Humanas e Sociais Aplicada, (1).

Grice, L. N., Nobel, C. E., Longshore, L., Huntley R. \& DeVierno, A. L. (2014). Life Cycle Carbon Footprint of Re-refined versus Base Oil that is not Re-refined. ACS Sustainable Chemistry \& Engineerig, 2(2), 158-164.

Hsu, Y. L. \& Liu, C.C. (2011). Evaluation and selection of regeneration of waste lubricating oil technology. Environ Monit Assess, 176(1-4), 197-212.

IPCC. Press Release: Climate change widespread, rapid, and intensifying (2021). Genova. Recuperado em 19 de out. 2021. <https://www.ipcc.ch/site/assets/uploads/2021/08/IPCC_WGIAR6-Press-Release_en.pdf>. 
Izza, H., Abdessalam, S. B., Bouida, M. \& Haddd, A. (2018). Recycling of used motor oil as an alternative method for production feedstock for the conversion processes. Petroleum Science and Technology, 36 (19), 1511-1515.

Kapustina, V., Havukainen, J., Virkki-Hatakka, T. \& Horttanainen, M. (2014). System analysis of waste oil management in Finland. Waste Management \& Research, 7(1).

Leite, P. R. (2009) Logística Reversa: meio ambiente e competitividade (2a ed.), São Paulo: Pearson Prentice Hall.

Lima, M.B.O. \& Viana, E. (2016). Geração e gerenciamento dos resíduos sólidos em uma oficina mecânica. Revista Eletrônica em Gestão, Educação e Tecnologia Ambiental, 20(1), 533551.

Martine, G. \& Alves, J. E. D. (2015). Economia, sociedade e meio ambiente no século 21: tripé ou trilema da sustentabilidade? Revista brasileira de estudos de população, 32(3), 433-460.

Milaré, E. (2011). Direito do Ambiente: a gestão ambiental em foco: doutrina, jurisprudência, glossário (7a ed.). São Paulo: Revista dos Tribunais.

Mota, A. K. V. \& Figueiredo, G. L. A. A. (2017). Destinação do óleo lubrificante usado ou contaminado OLUC nas oficinas mecânicas em uma pequena cidade localizada no norte do Estado do Tocantins. Facit Business and Technology Journal, 3 (1).

Nascimento, J. F., Teixeira, V. V. N., Menezes, J. E. C. \& Alves, K. R. C. P. (2016). A importância do gerenciamento de resíduos sólidos e sua logística reversa nos postos de combustíveis da cidade de Campina Grande-PB. Revista Produção e Desenvolvimento, 2(1), 64-76.

Nikolaidis, Y. (2013). Quality Management in Reverse Logistics. A Broad Look on Quality Issues and Their Interaction with Closed-Loop Supply Chains. University of Macedonia. London: Springer-Verlag.

Oliveira, A., Souza, R. D. S., Junior, P. D. S. P., Silva, W.S. \& Fraia, R. B. (2017). Benefícios socioambientais e econômicos a partir do rerrefino de óleos lubrificantes usados. Revista Educação Ambiental em Ação, 16(60).

ONU. Organização das Nações Unidas. Transformando Nosso Mundo: A Agenda 2030 para o Desenvolvimento Sustentável (2015). Nova Iorque: ONU, 2015. Recuperado em 19 de out. 2021. <https://nacoesunidas.org/wpcontent/uploads/2015/10/agenda2030-pt-br.pdf>.

Pires, A. \& Martinho, G. (2012). Carbon Footprint Analysis for the Waste Oil Management System in Portugal. British Journal Of Environment \& Climate Change, 3(2), 278-287.

Rac, A. \& Vencl, A. (2012). Ecological and technical aspects of the waste oils influence on environment. The 3rd International Conference on DIPRE. 18(1), 1-7.

Ribeiro, J. J. K., Chaves, G. L. D. \& Muniz, E. P. (2018). Avaliação da Coleta de Óleo Lubrificante Usado e Contaminado no Município de São Mateus. Revista Gestão \& Tecnologia, 18(1), 269-282. 
Silva, V. P. \& Souza, S.K.S. (2020). Environmental characterization of a filling station from the stand point of environmental adaptation. Research, Society and Development, 9(7).

Silveira, E. L. C., Caland, L. B. \& Moura, C. V. R. (2006). Determinação de contaminantes em óleos lubrificantes usados em esgotos contaminados por esses lubrificantes. Química Nova, 29, 1193-1197.

Stocker, E., Samoel, J.O.B., Heringer, E. \& Stocker, F. (2020). O processo da logística reversa e práticas de desenvolvimento sustentável: O caso da rerrefinação de óleo. Revista DELOS: Desarrollo Local Sostenible, 13(36), p. 22.

Tristão, J. A. M., Tristão, V. T. V. \& Frederico, E. (2017). O processo de reciclagem do óleo lubrificante. Revista Ibero-Americana de Ciências Ambientais, 8(2), 224-238.

Willing, A. (2001). Lubricants based on renewable resources-an environmentally compatible alternative to mineral oil products. Chemosphere, 43(1), 89-98. 